\title{
The use of probiotics to enhance immunity of broiler chicken against some intestinal infection pathogens
}

\section{Fatma M. Mohamed ${ }^{1 *}$, Manal H. Thabet ${ }^{2}$, Marwa F. Ali ${ }^{3 *}$}

${ }^{1}$ Department of Poultry Diseases, Animal Health Research Institute, Regional Laboratory, Assiut, Egypt, ${ }^{2}$ Department of Bacteriology, Animal Health Research Institute, Regional Laboratory, Assuit, Egypt, ${ }^{3}$ Department of Veterinary Pathology and Clinical Pathology, Faculty of Veterinary Medicine, Assuit University, Egypt

\begin{abstract}
This study was conducted on 120 one day old broiler chicks which were divided into six groups, 20 birds each. Group 1 (control), group 2 (supplemented with probiotic), group 3 (challenged with Salmonella and receive no probiotic), group 4 (challenged with $E$ coli and receive no probiotic), group 5 (challenged with Salmonella and supplemented with probiotic), group 6 (challenged with $E$ coli and supplemented with probiotic). The experiment extended for 30 days starting from one-day-old chicks. Body weights, clinical symptoms, haematological analysis and postmortem lesions were demonstrated on $8^{\text {th }}, 15^{\text {th }}$ and $30^{\text {th }}$ day of the experiment. Also, histopathological studies of the intestinal mucosa, liver, spleen, thymus and bursa of Fabricius, as well as immunostaining of surface antigens (CD3A in the thymus and CD79A in the spleen and bursae of Fabricius), were also investigated. The current study revealed that supplementation of probiotic alone obviously improved weight gains as compared to the control group.

Furthermore, probiotic supplementation decreased the colony forming a unit (CFU) of Salmonella enteritidis and E. coli (strain O2: H45) in the intestinal mucosa. Histopathologically, the intestinal mucosa showed an improvement which indicated by hyperplasia of the lining epithelium and abundance of goblet cells, but this local effect did not extend to other organs in the body that demonstrated mild to severe histopathological changes in challenged groups. The haematological analysis also verified that treatment with probiotics had no significant effect on most blood values (RBCs, WBCs and $\mathrm{Hb}$ ). However, the differential leucocytic counts were significantly influenced by dietary treatment with probiotics which caused a highly significant decrease in lymphocyte percentage. In conclusion, probiotics obviously improved the growth performance and local immune response in the intestine, however no clear evidence of improvement of the general immune status of the experimental birds.
\end{abstract}

Keywords: Probiotics, chicken, immunity, pathology.

DOI: $10.21608 / \mathrm{svu} .2019 .23141$

Received: September 9, $2018 \quad$ Accepted: November 14, 2018

Published: January 1, 2019

*Corresponding Author: Fatma M. Mohamed E-mail: elzuhry@yahoo.com

Citation: Mohamed et al., The use of probiotics to enhance immunity of broiler chicken against some intestinal infection pathogens. SVU-IJVS 2019, 2 (1): 1-19.

Copyright: (C) Mohamed et al. This is an open access article distributed under the terms of the creative common attribution license, which permits unrestricted use, distribution and reproduction in any medium provided the original author and source are created.

Competing interest: The authors have declared that no competing interest exists. 


\section{Introduction}

The increase in productivity of the poultry industry has been accompanied by various impacts, including the emergence of a large variety of pathogens and bacterial resistance. These impacts are in part due to the indiscriminate use of chemotherapeutic agents as a result of management practices in rearing cycles (Kabir, 2009). The increased use of antibiotics for therapeutic, prophylactic and growth promotion purposes led to the presence of antibiotic residues in poultry, meat and eggs which have the deleterious effect on human consumers that can cause the resistance of human flora and pathogenic microbes to those antibiotics (Abd-el-rahman et al., 2012).

In Europe and South Korea, growth promoting antibiotics have been banned since 2006 and 2012 respectively, and such bans are further expected to affect the rest of the world. The development topic for animal science research involved in developing sustainable animal production system, that in the absence of alternatives to antibiotics chicken raised under current intensive production systems face a higher risk of infection by enteric pathogens (Lillehoj and Lee, 2012). Probiotics are being considered to fill this gap, and already some farmers are using them instead of antibiotics (Trafalsk and Grzybowski, 2004).

Probiotics are "live microorganisms when administered in adequate amounts conferring a health benefit to the host". The most important advantage of probiotics is that they neither have any residues in animal products nor exerts any antibiotic resistance by consumption and probiotics have a good impact on the poultry performance (Koenen et al., 2004 and Mountzouris et al., 2007).
Lactobacilli species are commonly selected as probiotics since they express many crucial properties such as high tolerance to acid and bile, capability to adhere to intestinal surfaces, withstanding low $\mathrm{PH}$, gastric juice (antimicrobial activity), resisting antibiotics, producing exopolysaccharides and removing cholesterol (Ruiz et al., 2013 and Tulumoglu et al., 2013). Lactobacillus acidophilus or mixture supplementation of lactobacilli cultures to chickens significantly increase the levels of amylase enzyme through its colonising of the intestine and thus increasing the digestibility of nutrient (Dierck, 1989).

In broiler nutrition, probiotic species belonging to Lactobacillus, Streptococcus, Bacillus, Bifidobacterium, Enterococcus, Aspergillus, Candida and Saccharomyces have a beneficial effect on broiler performance, modulation of intestinal flora, intestinal histological changes, immunomodulation, in addition, have an impact on specific haemato-biochemical parameters and improving microbiological meat quality of broilers (Matsuzak and Chin, 2000; Islam et al., 2004; Matsuzaki et al., 2007; Apata, 2008 and Ashayerizadeh et al., 2009). Probiotics also regulate the microbial environment in the gut, thereby improve feed conversion ratio. In vitro and in vivo studies have demonstrated that lactic acid producing bacteria can inhibit the growth of poultry pathogens like Salmonella and $E$ coli by lowering the $\mathrm{PH}$ of the gut (Chaucheyras et al., 1995; Lee et al., 2003 and Frizzo et al., 2010).

Probiotics have been reported to cause enhancement of colonization resistance against pathogens as Salmonella enterica which colonize and penetrate the mucosal barrier. Probiotics also strengthen tight 
junctions between enterocytes and enhance the mucosal immune response to pathogens (Lei and Allan, 2001).

Probiotics reduce colonization and shedding of Salmonella and Campylobacter and are a useful measure to protect newly hatched chicks and other birds against Salmonella and other entomopathogens (Line et al., 1998; Fritts et al., 2000 and Schneitz, 2005).

Brisbin et al. (2008) investigated the spatial and temporal expression of immune system genes in chicken cecal tonsil in response to structural constituents of $L$. acidophilus which induced T-helper-1 cytokines in cecal tonsil cells. Also, several investigations demonstrated the potential effect of probiotic on immune modulation (Matsuzaki and Chin, 2000; Mathivanan and Kalaiarasi, 2007 and Apata, 2008).

The current study aims to evaluate the beneficial effect of probiotic on growth performance, haematological picture and favorable impact on immunity of broiler chicken against Salmonella enteritidis and $E$ coli infection and their consequent histopathological changes in different organs.

\section{Materials and Methods}

Cloacal swabs:

Sampling was done in the period between September-2017 to February 2018 in ten broiler chicken farms located in Assuit city, Egypt, whose birds ageing 27 to 35 days. From each farm, 20 individual cloacal swabs were randomly collected from birds suffered from respiratory and intestinal signs. Samples were transported in $1.5 \mathrm{ml}$ test tubes containing $750 \mu \mathrm{L}$ of brain heart infusion (BHI) broth then refrigerated in an ice box and sent to the laboratory of animal health research institute in Assuit governorate.

Isolation and Identification of the suspected bacteria:

For isolation of $E$ coli, BHI broth that used for transporting samples were incubated at $37^{\circ} \mathrm{C}$ for 18 hours, then a loopful of the incubated BHI broth was streaked in the plate containing Eosin Methylene Blue (EMB) agar. Colonies with the characteristic morphology (dark coloured colonies with a brilliant green sheen) were selected and identified with biochemical reactions (Quinn et al., 2002).

For the isolation of Salmonella sp., as done previously with $E$ coli a loopful of incubated BHI broth was transferred to Rappaport-Vassiliadis broth then incubated at $37^{\circ} \mathrm{C}$ for 24 hours. Samples were streaked on Brilliant Green agar added Novobiocin $(40 \mu \mathrm{g} / \mathrm{mL})$ and SalmonellaShigella agar and left for 24 hours at $37^{\circ} \mathrm{C}$. After incubation, colonies from each sample with characteristics morphology to Salmonella sp. were subjected to biochemical identification. Isolates with biochemical profile compatible with Salmonella spp. were identified serologically (Al-Aalim, 2017).

\section{Experimental birds:}

One-hundred- and twenty of one-dayold chicks were divided into six groups according to the ration received, 20 birds each group:

Group 1: control (only standard ration).

Group 2: (standard ration and probiotics).

Group 3: (standard ration and challenged with Salmonella).

Group 4: (standard ration and challenged with $E$ coli).

Group 5: (standard ration challenged with Salmonella and received probiotics).

Group 6: (standard ration challenged with E coli and received probiotics). 
The birds were reared under hygienic management practices throughout the entire period of study. Commercially available standard poultry feed (Feed mix, Egypt) was used for all groups throughout the experiment. The broiler chicks were fed with typical broiler starter, broiler grower and broiler finisher rations. As per instruction, probiotics were added to drinking water at a ratio of $0.5 \mathrm{~g} / 1$ litre water and was given daily to birds belonging to groups 2 and 5 and 6 . The experiment extended for 30 days from oneday-old until 30 days old chicks.

Body weight:

All chicks were individually weighed at $8^{\text {th }}, 15^{\text {th }}$ and $30^{\text {th }}$ days of the experiment and the average bird weight gains were determined.

\section{Clinical signs and lesions:}

Clinical signs and PM lesions were investigated throughout and at the end of the experiment.

\section{Haematological examination:}

Blood samples were collected via the wing vein from all groups at $8^{\text {th }}, 15^{\text {th }}$ and $30^{\text {th }}$ days of the experiment. About $2 \mathrm{ml}$ of blood were drained from each bird into a tube containing $1 \mathrm{mg}$ ethylene tetraacetic acid (EDTA). Total red blood cells (RBC) count, haemoglobin $(\mathrm{Hb})$ concentration, total white blood cells (WBC) count and differential leucocytic count were determined within 1-2 hours of collection. Haematological parameters were determined using (Medonic Auto Hematology Analyzer CA 620/ Vet/20).

\section{Histopathological examination:}

The chickens were sacrificed, and tissue specimens from bursa, thymus, spleen, lung, liver and intestine of all experimental groups were collected and fixed in $10 \%$ neutral buffered formalin. The tissues were prepared for routine histopathological examination (Bancroft and Stevens, 1982) and examined using the light microscope (Olympus CX31, Japan) and photographed using a digital camera (Olympus, Camedia C-5060, Japan).

\section{Immunohistochemistry investigations:}

Paraffin sections from the thymus, bursa of Fabricius and spleen were used for immunohistochemical detection of CD3 ( $\mathrm{T}$ - lymphocytes) in thymus and CD79 (B-lymphocytes) in spleen and bursa of Fabricius at the end of the experiment ( $30^{\text {th }}$ day). The tissue sections ( $3 \mu \mathrm{m}$ thick) were deparaffinized and hydrated then washed by distal water. Antigen retrieval was applied in a water bath using citrate buffer (pH6) for 20 minutes. The endogenous peroxidase activities were removed with 3\% hydrogen peroxide $\left(\mathrm{H}_{2} \mathrm{O}_{2}\right)$. Sections were then incubated in diluted polyclonal primary antibody for one hour at room temperature in a humidified chamber for CD79 (obtained from Novus Biologicus company) and CD3 polyclonal rabbit anti-human CD3 (Dako) at 1 in 300 dilutions. The primary antibodies were detected in all experimental groups. The staining was performed using Power-Stain ${ }^{\mathrm{TM}} 1.0$ Poly HRP DAB according to the manufacturer's instructions. Then the sections were rinsed three times for 5 min each with Phosphatebuffered saline, and the sections were incubated in Poly HRP Conjugate for 15 minutes at room temperature. A mixture of $\mathrm{DAB}$ chromogen visualized the sections, and DAB substrate then incubated for 10 minutes. Sections were washed by distilled water then counterstained with hematoxylin and dehydrated and mounted (Anis et al., 2013).

Scoring of immunoreactivity: 
The immunepositive cells were counted in 10 fields of the histological sections of tissues. Cytoplasmic CD79A positive cells were detected in the medulla of bursal follicles and white pulp of the spleen. Cytoplasmic CD3A positive cells were observed in the thymus. Positive cells were identified using digital an Axiostar plus microscope (Carl Zeiss, Thornwood, NY, USA) interfaced with an Axiostar plus digital camera and Axiovision 4.1 software (Carl Zeiss) at a magnification of 100, where B-lymphocytes and $\mathrm{T}$ lymphocytes were diffusely distributed, and their relative frequency per focus was calculated according to the point count method (Weibel, 1969).

\section{Statistical analysis:}

The variation in numbers of CD79A positive cells in bursa of Fabricius and spleen in addition to CD3A positive cells in the thymus (randomized block design) were compared among broilers in different experimental groups at the end of the study. Statistical analysis was performed by using the Statistical Package for the Social Sciences (SPSS), Version 16 for windows. Data are expressed as mean \pm SD was evaluated by two independent samples Test "Mann-Whitney U Test".

\section{Results}

\section{Clinical signs:}

Clinical signs included depression, weak growth, weakness, diarrhoea and dehydration particularly in groups challenged with Salmonella enteritidis and $E$ coli. Mortalities were mostly limited to the first two weeks of age and seen only in group 5 challenged with Salmonella and supplemented with probiotics (Table 1).

Table (1): The rate of morbidity and mortality in all experimental groups

\begin{tabular}{|l|c|c|}
\hline \multicolumn{1}{|c|}{ Group } & Morbidity & Mortality \\
\hline Group 1 (control) & $1 / 10$ & $0 / 10$ \\
\hline Group 2 (Probiotic group) & $0 / 10$ & $0 / 10$ \\
\hline Group 3 (Salmonella challenged) & $10 / 20$ & $0 / 20$ \\
\hline Group 4 E coli challenged) & $6 / 20$ & $0 / 20$ \\
\hline Group 5 (Salmonella + probiotic) & $10 / 20$ & $10 / 20$ \\
\hline Group 6 E coli + probiotic) & $6 / 20$ & $0 / 20$ \\
\hline
\end{tabular}

\section{Isolation and identification:}

E coli were isolated from $45 \%$ of the examined samples. In contrast, Salmonella isolates were isolated from $5 \%$ of individual cloacal swab samples. According to the serotyping, 12 out of 45 of the isolated $E$ coli were of strain $O 2$ : H45. However, 3 out of 5 positive Salmonella isolates were Salmonella enteritidis.

Body weight of the birds:

The current study revealed that the weight of the experimental birds recorded variable values between different groups (Table 2). The group receiving only probiotics in addition to the standard diet (group 2) showed the best weight gain among experimental groups. However, the group challenged with Salmonella and received no probiotics (group 3) recorded the least weight gain compared to other groups. Besides, the group challenged with E coli and received probiotics (group 6) recorded better weight gain compared to that challenged with Salmonella and received probiotics. 
Table (2): Weight of experimental birds (grams \pm SD) throughout the experiment

\begin{tabular}{|l|c|c|c|}
\hline \multirow{2}{*}{\multicolumn{1}{c|}{ Groups }} & \multicolumn{3}{|c|}{ Body weight } \\
\cline { 2 - 4 } & $\mathbf{8}^{\text {th }}$ day & $\mathbf{1 5}^{\text {th }}$ day & $\mathbf{3 0}^{\text {th }}$ day \\
\hline Group 1 (control) & $190.0 \pm 12.9$ & $500.5 \pm 15.2$ & $1333.7 \pm 72.3$ \\
\hline Group 2 (Probiotic group) & $210.5 \pm 13.2$ & $650.3 \pm 14.3$ & $1606.7 \pm 66.2$ \\
\hline Group 3 (Salmonella challenged) & $180.9 \pm 12.4$ & $490.4 \pm 12.2$ & $1050.8 \pm 81.2$ \\
\hline Group 4 E coli challenged) & $195.8 \pm 13.1$ & $485.5 \pm 16.7$ & $1260.1 \pm 75.4$ \\
\hline Group 5 (Salmonella + probiotic) & $186.2 \pm 12.7$ & $515.5 \pm 15.2$ & $1166.1 \pm 65.5$ \\
\hline Group 6 E coli + probiotic) & $194.4 \pm 12.9$ & $520.2 \pm 14.3$ & $1266.4 \pm 50.6$ \\
\hline
\end{tabular}

Bacterial colony forming units $(C F U)$ :

The CFU, in the group 5 (supplemented with probiotics and challenged with Salmonella enteritidis), recorded no change by the beginning of the second weeks; however, it demonstrated a noticeable decrease by the $30^{\text {th }}$ day of the experiment when compared to group 3. In the $E$ coli challenged group and supplemented with probiotics (group 6), the CFU showed a slight decrease only by the $30^{\text {th }}$ day of the experiment (Table 3 ).

Table (3): CFU/ml in challenged experimental groups

\begin{tabular}{|l|c|c|c|}
\hline \multirow{2}{*}{\multicolumn{1}{|c|}{ Groups }} & \multicolumn{3}{|c|}{ Colony count } \\
\cline { 2 - 4 } & $\mathbf{8}^{\text {th }}$ day & $\mathbf{1 5}^{\text {th }}$ day & $\mathbf{3 0}^{\text {th }}$ day \\
\hline Group 3 (Salmonella challenged) & $10 \times 10^{8}$ & $10 \times 10^{8}$ & $712 \times 10^{8}$ \\
\hline Group 4 $($ E coli challenged) & $420 \times 10^{8}$ & $128 \times 10^{8}$ & $320 \times 10^{8}$ \\
\hline Group 5 (Salmonella + probiotic) & $420 \times 10^{8}$ & $420 \times 10^{8}$ & $230 \times 10^{8}$ \\
\hline Group 6 E coli + probiotic) & $484 \times 10^{8}$ & $484 \times 10^{8}$ & $430 \times 10^{8}$ \\
\hline
\end{tabular}

Haematological parameters:

The result of haematological parameters in all chickens' broiler groups was presented in Table (4) and Figure (1). All measured haematological parameters for $\mathrm{RBC}, \mathrm{WBC}, \mathrm{HB}$, and monocytes\% showed no significant differences $(\mathrm{P}>$ 0.05). However, there was a highly significant decrease in lymphocytes percentage in group 2 (probiotic group) compared to the control (group 1), and a substantial decrease in lymphocytes percentage in group 3, group 5 and group 6 when compared with group 1 . On the other hand, the granulocytes percentage showed a highly significant increase in groups 2 and 6 and a substantial increase in group 3.

Table (4): Hematological parameters of different experimental groups

\begin{tabular}{|l|c|c|c|c|c|c|}
\hline \multicolumn{1}{|c|}{ Groups } & $\begin{array}{c}\mathbf{R B C} \\
\left(\mathbf{x 1 0}^{\mathbf{6}} \mathbf{m m}^{\mathbf{3}}\right)\end{array}$ & $\begin{array}{c}\mathbf{W B C} \\
\left(\mathbf{x 1 0}^{\left.\mathbf{3} / \mathbf{m m}^{\mathbf{3}}\right)}\right.\end{array}$ & $\mathbf{H b}(\mathbf{g} / \mathbf{d l})$ & $\begin{array}{c}\text { Lymphocytes } \\
\mathbf{\%}\end{array}$ & $\begin{array}{c}\text { Monocytes } \\
\mathbf{\%}\end{array}$ & $\begin{array}{c}\text { Granulocytes } \\
\mathbf{\%}\end{array}$ \\
\hline Group 1 (control) & $1.69 \pm 0.4$ & $3.43 \pm 0.6$ & $11.5 \pm 0.9$ & $64.6 \pm 3.8$ & $13.6 \pm 3.5$ & $22.0 \pm 0.8$ \\
\hline Group 2 (Probiotic group) & $2.49 \pm 0.7$ & $6.06 \pm 1.1$ & $13.7 \pm 2.8$ & $3.6 \pm 0.3$ & $74.03 \pm 1.2$ & $22.3 \pm 1.5$ \\
\hline Group 3 (Salmonella challenged) & $1.86 \pm 1.2$ & $5.06 \pm 0.9$ & $13.1 \pm 3.8$ & $11.7 \pm 6.4$ & $62.4 \pm 5.6$ & $25.9 \pm 5.9$ \\
\hline Group 4 (E coli challenged) & $1.97 \pm 0.8$ & $5.86 \pm 1.4$ & $12.7 \pm 2.0$ & $30.4 \pm 4.6$ & $52.2 \pm 40.8$ & $17.3 \pm 8.3$ \\
\hline Group 5 (Salmonella + probiotic) & $2.22 \pm 0.7$ & $5.06 \pm 1.4$ & $12.1 \pm 2.4$ & $17 \pm 10.4$ & $51.6 \pm 16.5$ & $31.2 \pm 6.6$ \\
\hline Group 6 $(\boldsymbol{E}$ coli + probiotic) & $1.57 \pm 0.8$ & $5.33 \pm 1.4$ & $8.8 \pm 4.4$ & $6.13 \pm 3.4$ & $73.4 \pm 11.1$ & $20.4 \pm 8.2$ \\
\hline
\end{tabular}

$\mathrm{RBC}=\mathrm{Red}$ blood cells counts $/ \mathrm{WBC}=$ Total white blood cells counts/ $\mathrm{Hb}=$ hemoglobin content. 

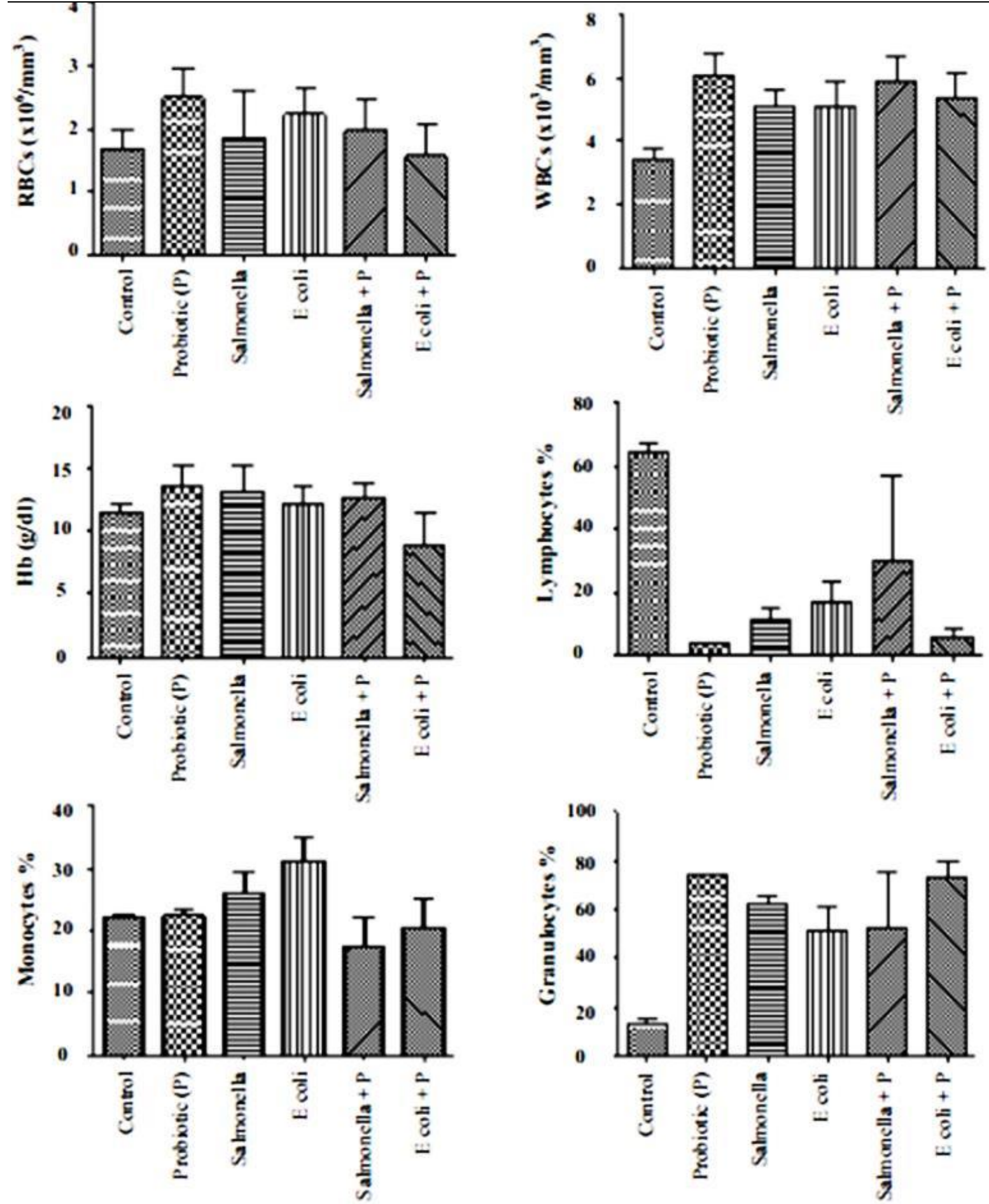

Fig. 1. Hematological parameter; RBC $\left(\times 10^{6} / \mathrm{mm}^{3}\right), \mathrm{WBC}\left(\mathrm{x} 10^{3} / \mathrm{mm}^{3}\right), \mathrm{Hb}(\mathrm{g} / \mathrm{dl})$, lymphocytes $\%$, monocytes $\%$, and granulocytes $\%$ (each value $=$ means of the samples at $8^{\text {th }}$, $15^{\text {th }}$ and $30^{\text {th }}$ day) in all experimental groups including control, probiotics, salmonella challenged, E coli challenged, salmonella challenged + probiotics, and E coli challenged + probiotics. 
Histopathological changes:

Lesions included an enlarged liver with necrosis, unabsorbed yolk sac and enteritis with necrotic lesions in the mucosa. Sometimes there were no lesions due to acute death caused by septicemia. Older birds could have the fever, being pale, dehydrated, and had diarrhoea. Also, the liver was swollen, brittle and often bile-stained

\section{Liver:}

In the control group, the liver showed normal hepatic tissue consisting of a central vein (C.V.) surrounded by radiating hepatic cords (Fig 2A). Liver of chickens supplemented with probiotics for 15 days was almost normal with uncommon, mild vacuolar degeneration of hepatocytes (Fig 2B). The Salmonella challenged group showed mild vacuolar degeneration of hepatocytes with the proliferation of mononuclear cells on the $15^{\text {th }}$ day of the
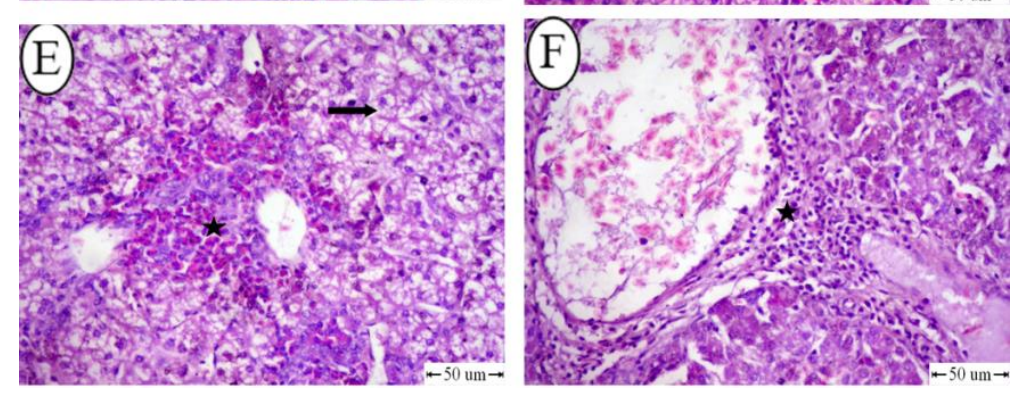

experiment (Fig 2C). These changes increased at the end of the study ( $30^{\text {th }}$ day) and became accompanied by congestion of blood vessels. Livers of salmonellainfected birds and immunized with probiotics after 15 days and until the end of the study showed severe vacuolar degeneration in hepatocytes (Fig 2D). In $E$ coli infected group, liver showed characteristic lesions of $E$ coli. Liver showed perivascular haemorrhage and vacuolar degeneration of hepatocytes 15 days post-infection (Fig 2E). These changes continued until 30 days postinfection. The examined liver of $E$ coli infected chickens and 15 days posttreatment with probiotics showed perivascular infiltration with inflammatory cells (Fig 2F). Birds sacrificed 30 days post-treatment showed mild vacuolar degeneration with an appearance of focal areas of Kupffer cells.
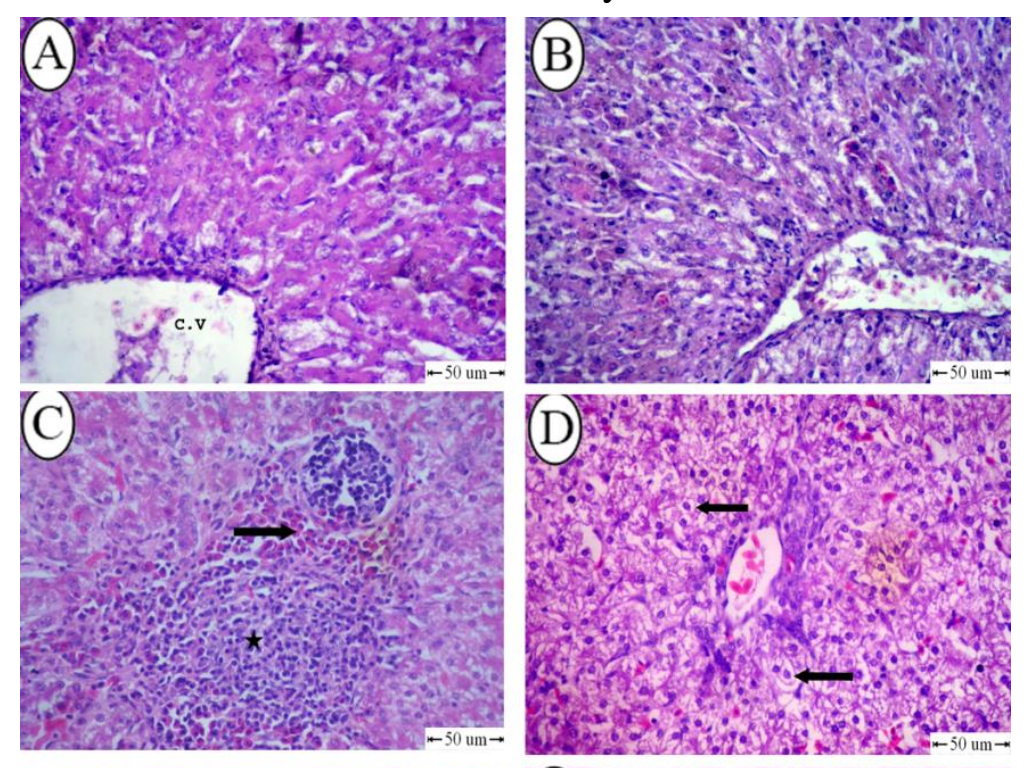

Fig. 2. Histopathological examination of the liver in (A) control group showing central vein (C.V.) surrounded by radiating hepatic cords. (B) The probiotic-treated group is showing mild vacuolar degeneration of hepatocytes. (C) (Salmonella-infected group) Fifteen days post-infection showing proliferation of mononuclear cells (star) and focal haemorrhage (arrow). (D) (Salmonella-infected group and challenged with probiotics) showing severe vacuolar degeneration in hepatocytes (arrow) (E) (E coli infected group) 15 days postinfection showing perivascular haemorrhage (star) and ballooning degeneration (arrow). (F) $\boldsymbol{E}$ coli infected group and challenged with probiotics showing perivascular infiltration with inflammatory cells (star), bar=50. H \& E. 


\section{Intestine:}

Microscopically, intestine of the control group showed intestinal villi with intact epithelium (Fig 3A). After 15 days, the gut of probiotics treated group, showed hyperplasia of goblet cells which became more evident on the $30^{\text {th }}$ day of the experiment (Fig 3B). In cecum of the Salmonella-infected group, desquamation of epithelium, interstitial haemorrhage in lamina propria was observed after 30 days (Fig 3C). Salmonella-infected birds and immunized 30 days post-treatment with probiotics, cecum showed intact epithelium with mild depletion in cecal tonsils (Fig 3D). Duodenum of $E$ coli challenged group showed severe desquamation of epithelium after 15 days from exposure which also observed after 30 days (Fig 3E). Similar changes characterized by severe desquamation of epithelium were found in the intestine of $E$ coli infected group and challenged with probiotics and examined after 15 days and 30 days (Fig 3F).
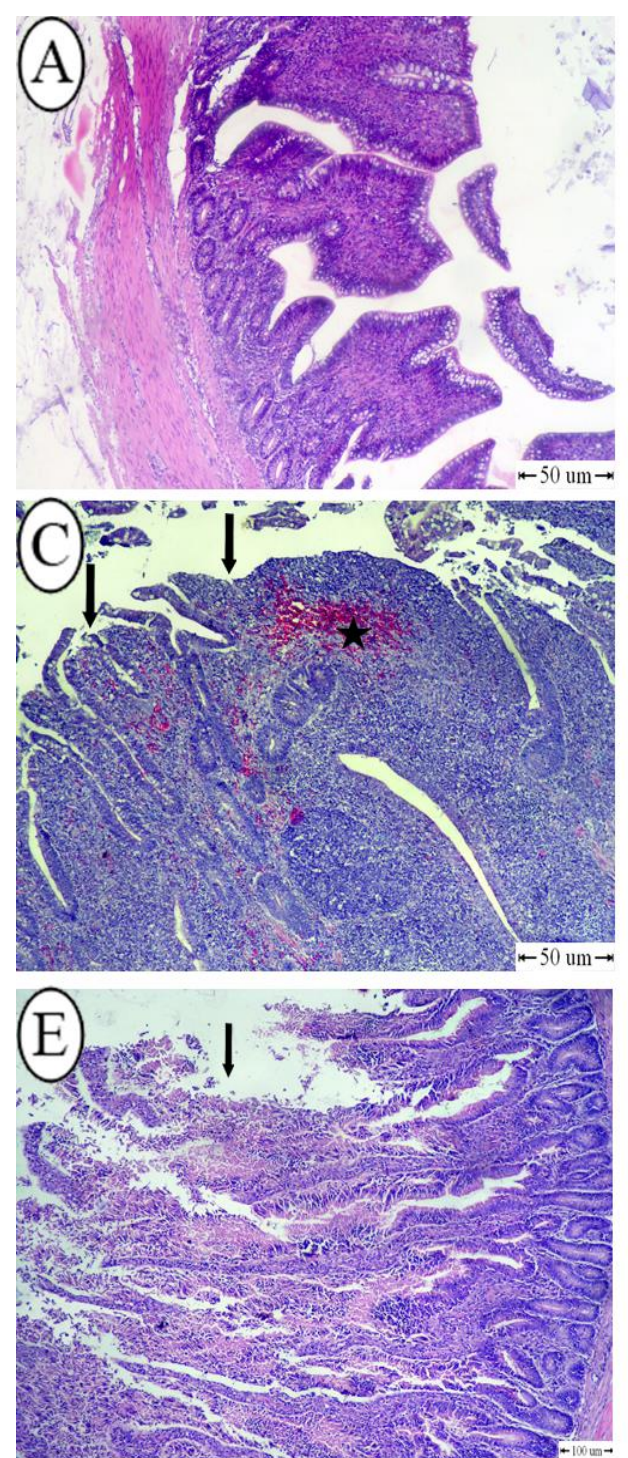
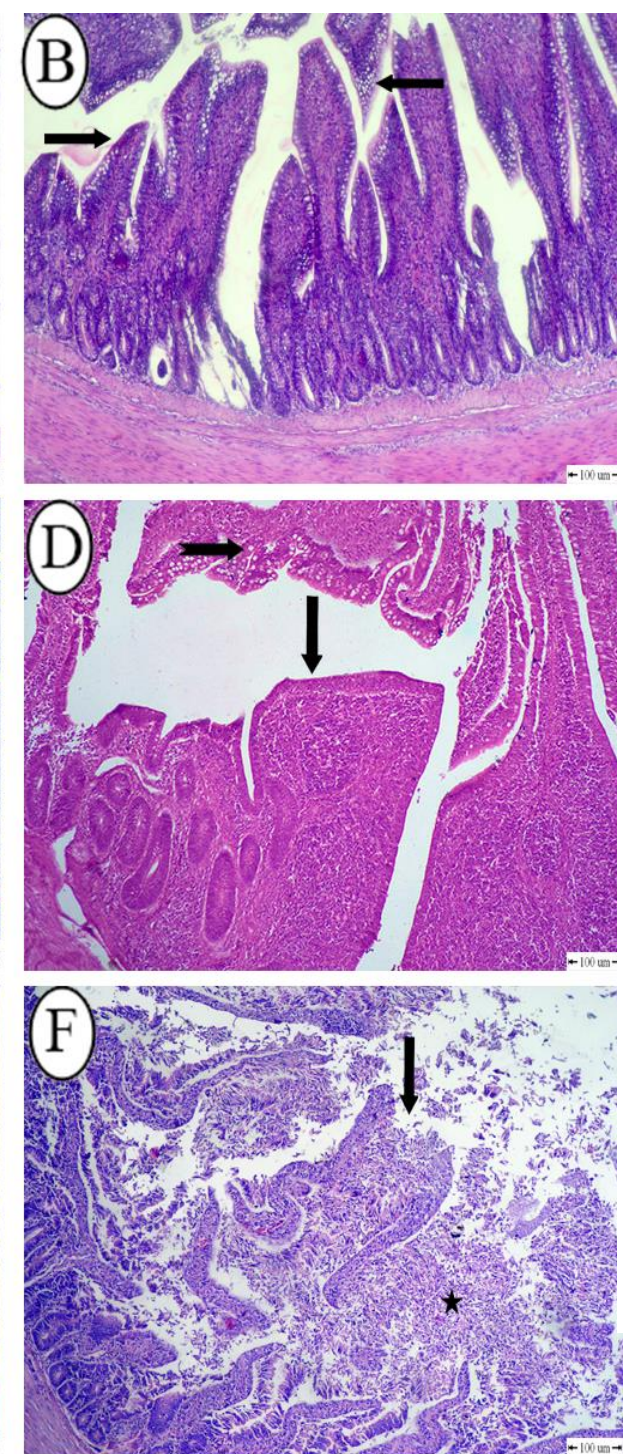

Fig. 3. Histopathological examination of the intestine in (A) Control group showing intact epithelium. (B) Probiotics treated group showing hyperplasia of goblet cells (arrow). (C) (Salmonellainfected group) Cecum 30 days post-infection showing desquamation of epithelium (arrow) and interstitial haemorrhage in lamina propria (star). (D) (Salmonella-infected group and challenged with probiotics) Cecum 30 days post-treatment showing intact mucosal epithelium (arrow) and activation with hyperplasia of goblet cells (notched arrow). (E) (E coli infected group) Intestine 30 days post-infection showing severe desquamation of epithelium (arrow). (F) (Ecoli infected group and challenged with probiotics) Intestine 30 says post-treated showing severe desquamation of epithelium (arrow) and tissue debris filled the lumen (star), bar=100. H \& E. 


\section{Spleen:}

Spleens of the control group showed normal architecture consists of white and red pulp (Fig 4A). At the end of the experiment, depletion in different areas of the spleen was seen in probiotics treated group (Fig 4B). Spleen showed a severe reduction in lymphoid cells of white pulp in the Salmonella-infected group (Fig 4C). In Salmonella-infected and probiotics supplemented group showed dilatation of
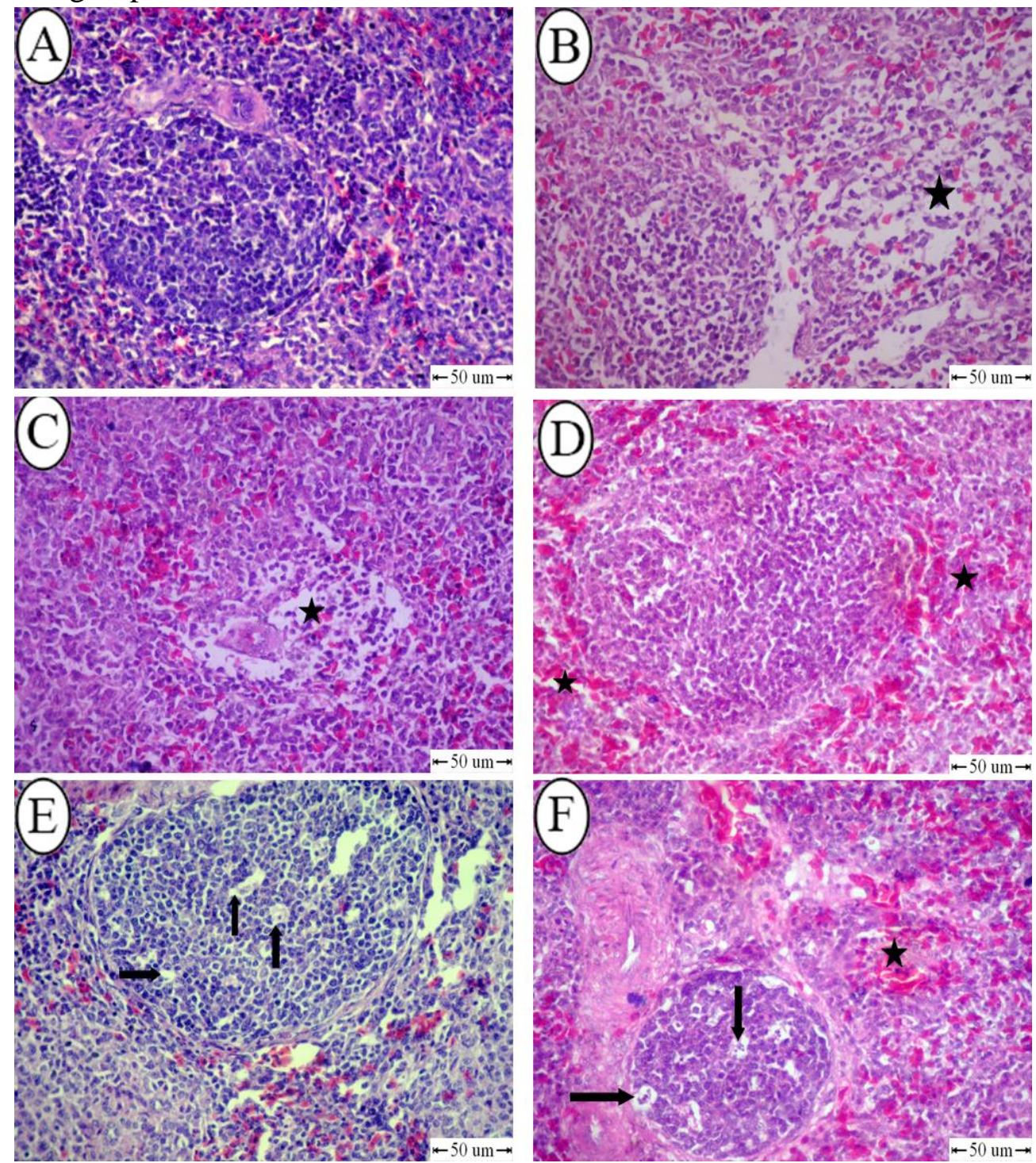

Fig. 4. Histopathological examination of the spleen in (A) Control group showing normal white and red pulp. (B) The probiotic-treated group was showing necrosis in red pulp (star). (C): (Salmonella-infected group) 30 days post-infection showing severe depletion in white pulp (star). (D) (Salmonella-infected group and challenged with probiotics) showing dilatation of blood sinusoids of red pulp (star). (E (E coli infected group) 
30 days post-infection showing apoptosis with nuclear debris in white pulps (arrow). (F) (E coli infected group and challenged with probiotics) showing dilatation of blood sinusoids of red pulp (star), apoptotic lymphocytes with nuclear debris in white pulps (arrow), bar=50. H \& E.

\section{Bursa of Fabricius:}

Bursas of the control group showed bursal follicle consisting of cortex, medulla and follicular associated epithelium. Bursal follicles were covered with pseudostratified columnar surface epithelium and separated by inter-follicular connective tissue (Fig 5A). Probiotics treated group showed hyperplasia of epithelium, thickening of subepithelial connective tissue stroma with the formation of small cysts (Fig 5B). Slight depletion of lymphoid follicles with epithelial formation cysts was also observed in bursa of a Salmonella-infected group in all examined birds during the experiment (Fig 5C). Salmonella-infected and probiotics supplemented group showed moderate depletion of lymphoid cells in bursal follicles with the formation of epithelial cysts after 15 days which increased on reaching $30^{\text {th }}$ day of the experiment and was associated with interstitial oedema (Fig 5D). Bursal follicles of $E$ coli infected group showed severe depletion and lysis of lymphoid cells after 30 days from infection with the appearance of multiple epithelial cysts (Fig $5 \mathrm{E})$. In $E$ coli infected, and probiotics supplemented group, the changes of the bursa in birds sacrificed 15 and 30 days post-infection were minimal. They were expressed by congestion of blood vessels and subepithelial oedema in connective tissue stroma with the formation of the small number of epithelial cysts (Fig 5F).

Immunohistochemistry of (thymus, bursa and spleen):

Detection of CD3A positive cytoplasmic reaction in the thymus in different groups showed a significant decrease in group 1 in comparison to group 2. On comparing between group 3 and group 5, the quantification of $\mathrm{CD} 3 \mathrm{~A}$ positive cells displayed a significant increase in group 3. Also, the immunoreactivity increased slightly in the thymus of broiler chickens in group 4 when compared to group 6. Lymphoid follicles in bursa showed strong positive immunoreactivity of $\mathrm{CD} 79 \mathrm{~A}$ positive cytoplasmic reaction in group 1 when compared to group 2, while, the response in other groups showed non-significant variation between them. The reactive $C D$ 79A positive cells in the spleen of different groups showed non-significant variation between them (Table 5 and Fig 6).

Table (5): Mean number of CD3A positive cells in the thymus and CD79A positive cells in bursa of Fabricius and spleen in broiler chicken in all experimental groups.

\begin{tabular}{|c|c|c|c|c|c|c|}
\hline Positive Cells & $\begin{array}{c}\text { Group 1 } \\
\text { (Control) }\end{array}$ & $\begin{array}{c}\text { Group 2 } \\
\text { (Probioti } \\
\text { c) }\end{array}$ & $\begin{array}{c}\text { Group 3 } \\
\text { (Salmonell } \\
\text { a) }\end{array}$ & $\begin{array}{c}\text { Group 5 } \\
(\text { Salmonella }+ \\
\text { P) } \\
\end{array}$ & $\begin{array}{c}\text { Group } 4 \\
\text { (E Coli) }\end{array}$ & $\begin{array}{c}\text { Group 6 } \\
(\text { E Coli }+ \text { P })\end{array}$ \\
\hline CD3A in Thymus & $112.6 \pm 13.55$ & $48.2 \pm 9.73$ & $96.4 \pm 11.10$ & $77 \pm 5.47$ & $61.8 \pm 4.43$ & $34.4 \pm 8.11$ \\
\hline $\mathbf{P} *$ Value & \multicolumn{2}{|c|}{0.043} & \multicolumn{2}{|c|}{0.042} & \multicolumn{2}{|c|}{0.043} \\
\hline CD79A in Bursa & $78.6 \pm 3.97$ & $65.6 \pm 9.81$ & $83.8 \pm 6.64$ & $53 \pm 4.96$ & $21.6 \pm 3.64$ & $13.6 \pm 2.51$ \\
\hline $\mathbf{P} *$ Value & \multicolumn{2}{|c|}{0.043} & \multicolumn{2}{|c|}{0.059} & \multicolumn{2}{|c|}{0.068} \\
\hline $\begin{array}{l}\text { CD 79A in } \\
\text { Spleen }\end{array}$ & $58.25 \pm 2.36$ & $90.4 \pm 4.03$ & $51.5 \pm 7.85$ & $34.25 \pm 4.11$ & $32.5 \pm 9.32$ & $49 \pm 9.20$ \\
\hline $\mathbf{P} *$ Value & \multicolumn{2}{|c|}{0.059} & \multicolumn{2}{|c|}{0.068} & \multicolumn{2}{|c|}{0.144} \\
\hline
\end{tabular}

*P value by Mann-Whitney U Test 

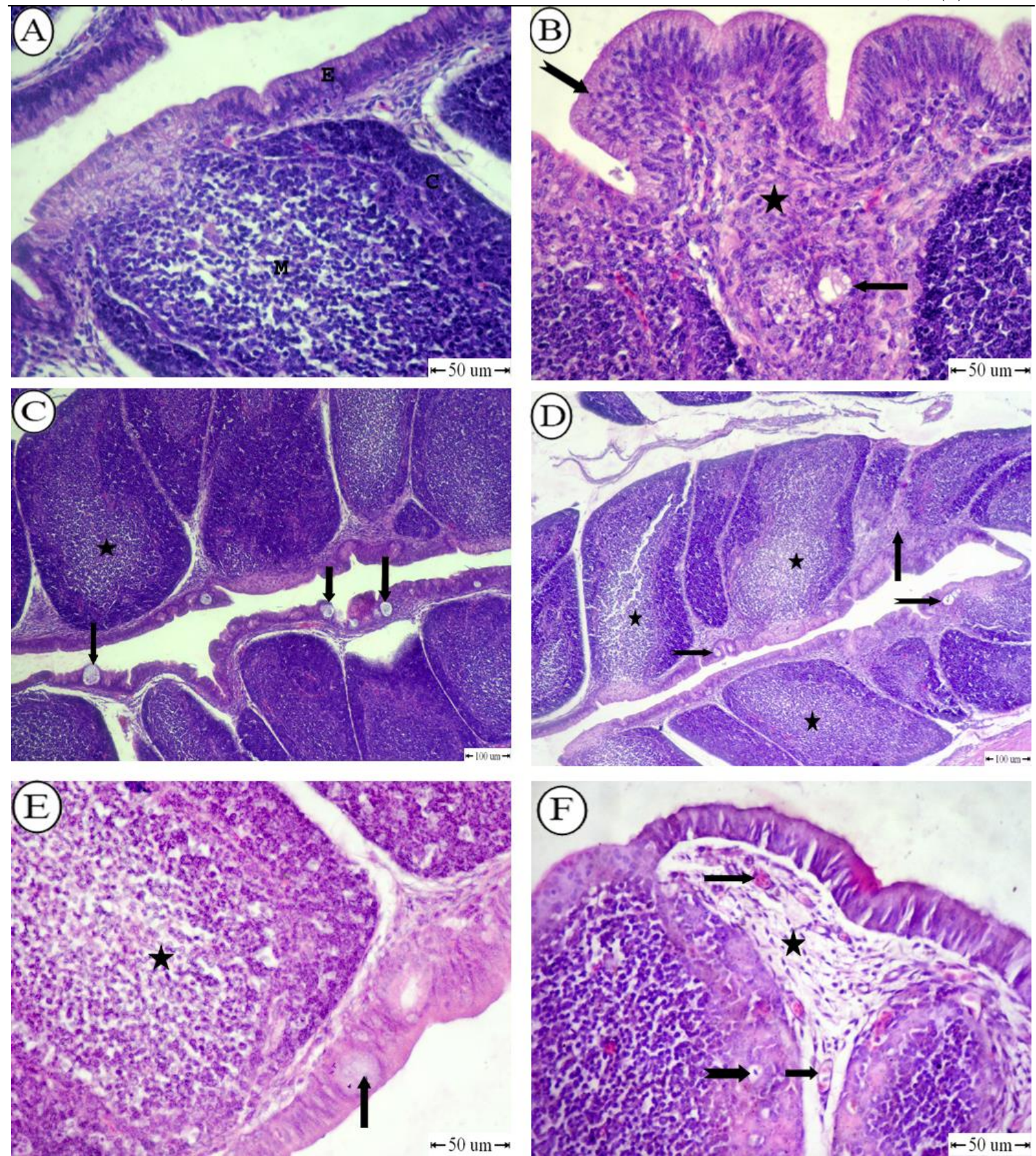

Fig. 5. Histopathological examination of bursa of Fabricius in (A) (control group) showing bursal follicles consist of the cortex of the follicle (C), medulla (M) of the follicle and inter-follicular surface epithelium. bar=50. (B) Probiotic-treated group showing hyperplasia of epithelium (notched arrow), thickening of subepithelial connective tissue stroma (star) and formation of small cysts(arrow), bar=50. (C) (Salmonellainfected group) Thirty days post-infection showing mild depletion of lymphoid follicles (star) formation epithelial cysts (arrow). bar=100. (D) (Salmonella-infected group and challenged with probiotics) Bursa was showing moderate depletion of lymphoid cells of bursal follicles (star) and formation of multiple small epithelial cysts (arrow), bar=100. (E) (E coli infected group) Thirty days post-infection showing severe depletion and lysis of bursal follicles (star) and presence of epithelial cysts (arrow), bar=50. (F) (E-coli infected group and challenged with probiotics) showing congestion of blood vessels (arrow) and subepithelial oedema in connective tissue stroma (star) with the formation of epithelial cysts (notched arrow), bar=50 H \& E. 

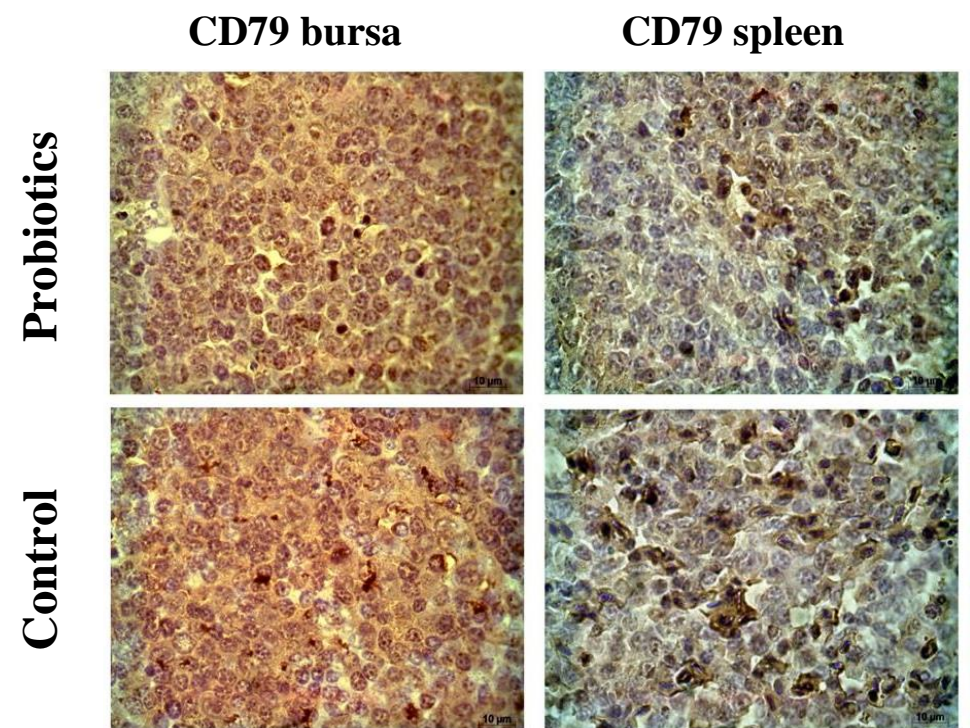

CD3 thymus
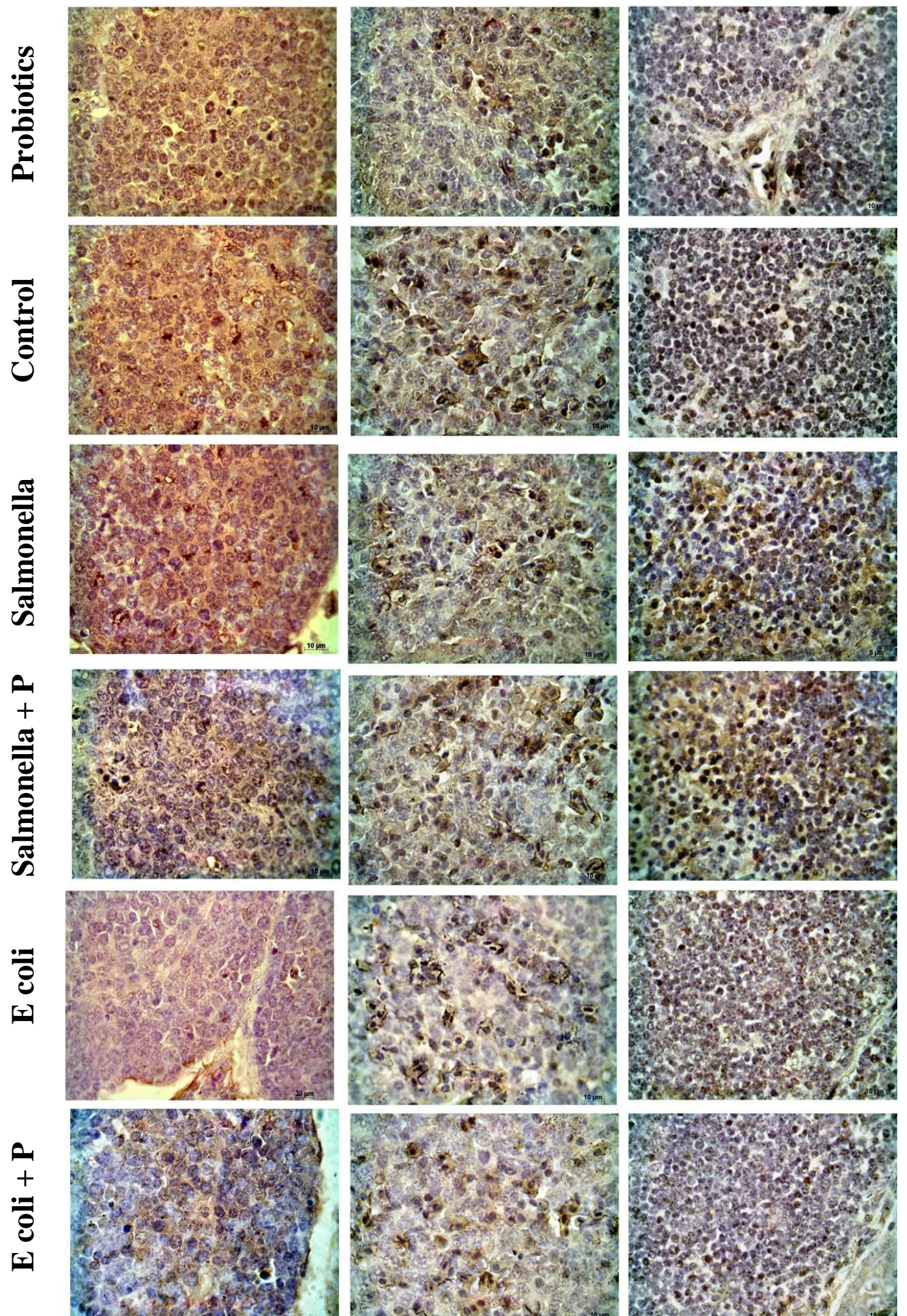

Fig. 6. Immuno-stained sections of broiler chickens in different groups showing CD 3 immune-positive cells in the thymus and CD 79 immune positive cells in lymphoid follicles of bursa of Fabricius and white pulp of spleen. Bar $=10$. 


\section{Discussion}

A maximum increase in the body weight was demonstrated in the group receiving probiotics in addition to the standard diet (group 2) compared to the control (group 1) and the challenged groups with or without probiotic supplementation. The group challenged with Salmonella enteritidis recorded the least weight gain among all experimental groups. The current improved weight gain in the probiotic-treated group is concurrent with the observation reported by Chiang and Hsieh (1995), Omprakash et al. (1996) and Owosibo et al. (2013). This maximum improvement of the weight gain in the probiotic-treated group might be due to maintaining healthy intestinal flora by competitive exclusion and antagonism, increasing digestive enzyme activities and promoting digestion rate of energy nutrient as it has been stated by Owosibo et al. (2013).

Similar to the results of Shibat Elhamd and Mohamed (2016), probiotic supplementation improved local intestinal immunity in broiler chickens and caused a decrease in the CFU of Salmonella enteritidis and $\mathrm{E}$ coli (O2: $\mathrm{H} 45$ ) challenged groups. The probiotics-containing Lactic acid produces an unfavorable $\mathrm{pH}$ for growth of Salmonella (Alkoms et al., 2000; Rolfe, 2000 and Johansen et al., 2004). Also, the decrease in CFU could be attributed to the competitive exclusion of lactobacilli to the enteric bacteria (Heres et al., 2003). Unlikely, Andino et al. (2014) mentioned that the probiotic did not afford protection from infection with Salmonella in an in vivo experiment in mice.

The data of the haematological parameters of broiler chickens' blood profiles were comparable. Treatment with probiotics had no significant effect on most measured blood values (RBCs, WBCs and
$\mathrm{Hb}$ ), a result that agrees with previous studies reported by Djouvinov et al. (2005), Alkhalf et al. (2010), Owosibo et al. (2013) and Abudabos et al. (2016). On the other hand, the differential leucocytic counts were significantly $(\mathrm{P}<0.05)$ influenced by dietary treatment with probiotics, where the probiotic-treated group (Group 2) showed a highly significant decrease in lymphocyte percentage. This result is consistent with those of Lillehoj and Chung (1992), Kamruzzaman et al. (2005) and Owosibo et al. (2013), but it disagrees with the findings of Shibat El-hamd and Mohamed (2016) who observed a significant increase of lymphocytes count in probiotic-treated broiler chicken. The constant intake of lactobacilli probiotics has been mentioned to induce a local immune-stimulant effect on the intestinal mucosa that attracts lymphocytes to the intestinal lamina propria causing a decrease in lymphocyte percentage in the blood (Lillehoj and Chung, 1992). The current highly significant reduction in lymphocyte percentage in challenged groups $(3,4,5$ and 6) compared to the control group simulates the findings of Kokosharov (2002) and Shibat El-hamd and Mohamed (2016).

The current study showed a highly significant $\quad(\mathrm{P}<0.05) \quad$ increase in granulocytes percentage in probioticsupplemented and $E$ coli + Probiotic treated groups when compared with control group. These results agree with that reported by Shibat El-hamd and Mohamed (2016) but disagree with the experimental model of Kokosharov (2002) who indicated that a peak level of myelocytes and young granulocytes production were enhanced from bone marrow one hour after a single injection of salmonella gallinarum endotoxin in mature birds because of its essential role as phagocytic cells. 
The histopathological examination of a liver of broilers in the group supplemented with probiotics showed mild vacuolar degeneration of hepatocytes. The intestine, however, showed hyperplasia of the lining epithelium and abundance of goblet cells. These results partly simulate the findings of Ghalib et al. (2018) who mentioned that probiotic alone causes mild vacuolar degeneration when compared with the control group. In this concern, Caspary (1992) indicated that the increased height of the intestinal villi increases the intestinal surface area which could improve the absorption of available nutrients. Also, Langhout et al. (1999) and Shamoto and Yamauchi (2000) suggested that increasing villus height in the intestine may indicate an enhanced function of the intestinal villi. Moreover, Brahmankar et al. (2011) reported that an increase in the mucus production which may be due to increasing the activity of intestinal gland and he suggested that this enhances dietary absorption which may explain the apparently improved weight gain in the group supplemented with probiotics in the current study.

Although probiotic supplementation, in the present study, improved local intestinal immunity in broiler chickens and caused a decrease in the colony forming unit of Salmonella enteritidis and $E$ coli (O2: H45) in challenged groups, these groups showed severe vacuolar degeneration of hepatocytes, congestion of splenic red pulp and mild depletion of bursal follicles. These findings may indicate that probiotics had only a local beneficial effect on the intestine and this effect did not extend to other organs in the body. This suggestion was supported by the current findings that the cecum of group supplemented with probiotics showed intact epithelium. In the same concern, it has been supposed that probiotics reduce intestinal colonization of salmonella by competing for iron (Deriu et al., 2013).

The current immunohistochemical findings on the surface antigens (CD3A) in the thymus and CD79A in the bursa and spleen indicated that probiotics seem to have no effect on activating the two immune organs. However, Andino et al. (2014) believe that probiotics could ameliorate immune response but enough time between probiotic administration and Salmonella infection may be crucial to allow the immune system to enhance protection against disease.

\section{Conclusions}

Probiotics obviously improved the growth performance and local immune response in the intestine, however there is no clear evidence of improving general immune status of the experimental birds.

\section{Conflict of interest statement}

The authors declare that they have no conflict of interest.

\section{References}

Abd-el-rahman AH, Kamel HH, Ahmed WM, Mogoda OSH, Mohamed AH (2012). Effect of Bactocell ${ }^{\circledR}$ and Revitilyte-Plustm as Probiotic Food Supplements on the Growth Performance, Hematological, Biochemical Parameters and Humoral Immune Response of Broiler Chickens. World Applied Sciences Journal, 18 (3): 305-316

Abudabos AM, Murshed MA, Qaid MM, Abdelrahman AG (2016). Effect of Probiotics on Serum Biochemical and Blood Constituents in Chicken Challenged with Salmonella enterica Subsp Typhimurium. Tropical 
Journal of Pharmacological Research, 15 (3): 461-467.

Alkhalf A, Alhaj M, Al-homidan I (2010). Influence of probiotic supplementation on blood parameters and growth performance in broiler chickens. Saudi Journal of Biological Sciences, 17: 219-225.

Alkoms HL, Skytta E, Saaela M, Maltila T, Latra K, Helender IM (2000). Lactic acid permeabilizes Gramnegative bacteria by disturbing the outer membrane. Applied and Environmental Microbiology, 66: 2001-2005.

Andino A, Zhang N, Diaz-Sanchez S, Yard C, Pendleton S, Hanning I (2014). Characterization and specificity of probiotics to prevent Salmonella infection in mice. Functional Foods in Health and Disease, 4(8): 370380 .

Anis Z, Morita T, Azuma K, Ito H, Ito T, Shimada A (2013). Comparative study on the pathogenesis of the generated 9a5b Newcastle disease virus mutant isolate between chickens and waterfowl. Veterinary pathology, 50(4): 638-647

.Apata DF (2008). Growth performance, nutrient digestibility and immune response of broiler chicks fed diets supplemented with a culture of Lactobacillus bulgaricus. Journal of the Science of Food and Agriculture, 88: 1253-1258.

Ashayerizadeh A, Dabiri N, Ashayerizadeh $\mathrm{O}$, Mirzadeh $\mathrm{KH}$, Roshanfekr $\mathrm{H}$, Mamooee M (2009). Effect of dietary antibiotic, probiotic and prebiotic as growth promoters, on growth performance, carcass characteristics and hematological indices of broiler chickens. Pakistan
Journal of Biological Sciences, 12: 52-57.

Bancroft JD, Stevens A (1982). Theory and Practice of Histological Techniques, Churchill Livingstone, NY. pp: 188-190.

Brahmankar MG, Wagh SB, Kale DB, Joshi MV (2011). Immunotoxicity of lead acetate in broiler birds. Journal of advances in pharmacy and healthcare Research.

Brisbin JT, Zhou H, Gong J, Sabour P, Akbari MR, Haghighi HR, Yu H, Clarke A, Sarson AJ, Sharif S (2008). Gene expression profiling of chicken lymphoid cells after treatment with Lactobacillus acidophilus cellular components. Developmental \& Comparative Immunology, 32: 563-574.

Caspary FW (1992). Physiology and pathophysiology of intestinal absorption. The American journal of clinical nutrition., 55: 299-308.

Chaucheyras F, Fonty G, Bertin G, Gouet P (1995). In vitro H2 utilization by a ruminal acetogenic bacterium cultivated alone or in association with an Archaea methanogen is stimulated by a probiotic strain of Sacharomyces cerevisiae. Applied and Environmental Microbiology, 61: 3466-3467.

Chiang, S H, Hsieh W M (1995). Effect of direct-fed microorganisms on broiler growth performance and litter ammonia level. AsianAustralasian Journal of Animal Sciences, 2: 159-162.

Deriu E, Liu JZ, Pezeshki M, Edwards RA, Ochoa RJ, Contreras H, Libby SJ, Fang FC, Raffatellu M (2013). Probiotic bacteria reduce Salmonella typhimurium intestinal colonization 
by competing for iron. Cell host \& microbe, 14 (1): 26-37.

Dierck NA (1989). Biotechnology aids to improve feed and feed digestion: Enzymes and fermentation. Archives of Animal Nutrition, 39: 241-261.

Djouvinov D, Boicheva S, Simeonova1T, Vlaikova T (2005). effect of feeding Lactina ${ }^{\circledR}$ probiotic on performance, some blood parameters and cecal microflora of ducklings. Trakia Journal of Sciences, 3 (2): 22-28.

Fritts CA, Hersey JH, Moti MA, Kroger EC, Yan F, SI J, Jiang Q, Campos MM, Waldroup AL, Waldroup PW (2000). Bacillus subtilis C-3102 (Calsporin) improves live performance and microbiological status of broiler chickens. Journal of Applied Poultry Research, 9: 149155.

Frizzo, LS, Sotto LP, Zbrun MV, Bertozzi E, Sequeira G, Armesto RR, Rosmini MR (2010. Lactic acid bacteria to improve growth performance in young calves fed milk replacer and spray-dried whey powder. Animal Feed Science and Technology, 157: 159167.

Ghalib, N, Al-Allaaf, ESh, Abdullha ST (2018). Histopathological study of chick intestine: Effect of probiotic and lead. Rafidain Journal of Science, 27: 8-14.

Heres L, Wagenaar JA, van Knapen F, Urlings BA (2003). Passage of Salmonella through the crop and gizzard of broiler chickens fed with fermented liquid feed. Avian Pathology, 32(2):173-181.
Islam MW, Rahman MM, Kabir SML, Kamruzzaman SM, Islam MN (2004). Effect of probiotics supplementation on growth performance and certain haematobiochemical parameters in broiler chickens. Bangladesh Journal of Veterinary Medicine, 2(1): 39-43.

Johansson JF, Paul LR, Finlay RD (2004). Microbial interactions in the mycorrhizosphere and their significance for sustainable agriculture. FEMS microbiology Ecology, 48(1): 1-13.

Kabir SML (2009). The role of probiotics in the poultry industry. International Journal of Molecular Sciences, 10(8): 3531-46.

Kamruzzaman SM, Kabir SML, Rahman MM, Islam MW, Reza MA (2005). Effect of probiotics and antibiotics supplementation on body weight and certain haemato-biochemical parameters in broilers. Bangladesh Journal of Veterinary Medicine, 3 (2): 100-104.

Koenen ME, Kramer J, van der Hulst R, Heres L, Jeurissen SHM, Boersma WJA (2004). Immunomodulation by probiotic lactobacilli in layer and meat-type chickens. British Poultry Science, 45: 355-366.

Kokosharov T (2002). Clinical and hematological effects of Salmonella gallinarum endotoxin in cockerels. Veterinarski Archiv, 72 (5): 269276.

Langhout DJ, Schutte JB, Van Leeuwen P, Wiebenga J, Tamminga S (1999). Effect of dietary high and low methylated citrus pectin on the activity of the ileal microflora and morphology of the mall intestinal 
wall of broiler chicks. British Poultry Science, 40: 340-347.

Lee YK, Puong KY, Ouwehand AC, Salminen S (2003). Displacement of bacterial pathogens from mucus and Caco-2 cell surface by lactobacilli. Journal of Medical Microbiology, 52: 925-930.

Lu L, Walker WA (2001). Pathologic and physiologic interactions of bacteria with the gastrointestinal epithelium. The American journal of clinical nutrition, 73(6), 1124S-1130S.

Lillehoj HS, Chung KS (1992). Tlymphocyte subpopulations in the intestinal intraepithelium and lamina propria in chickens. Veterinary Immunology and immunopathology, 31: 347-360.

Lillehoj HS, Lee KW (2012). Immune modulation of innate immunity as alternatives-to-antibiotics strategies to mitigate the use of drugs in poultry production. Poultry Science, 91: 1286-1291.

Line EJ, Bailey SJ, Cox NA, Stern NJ, Tompkins T (1998). Effect of yeastsupplemented feed on Salmonella and Campylobacter populations in broiler. Poultry Science, 77: 405410.

Mathivanan R, Kalaiarasi K (2007). Panchagavya and Andrographis paniculata as alternative to antibiotic growth promoters on haematological, serum biochemical parameters and immune status of broilers. The Journal of Poultry Science, 44: 198-204.

Matsuzaki T, Chin J (2000). Modulating immune responses with probiotic bacteria. Immunology \& Cell Biology, 78: 67-73.
Matsuzaki T, Takagi A, Ikemura $\mathrm{H}$, Matsuguchi T, Yokokura T (2007). Intestinal microflora: probiotics and autoimmunity. The Journal of Nutrition Supplement; 137: 798S$802 \mathrm{~S}$.

Mountzouris KC, Tsirtsikos P, Kalamara E, Nitsch S, Schatzmayr G, Fegeros K (2007). Evaluation of the efficacy of a probiotic containing Lactobacillus, Bifidobacterium, Enterococcus, and Pediococcus strains in promoting broiler performance and modulating cecal microflora composition and metabolic activities. Poultry Science, 86(2): 309-317.

Omprakash AV, Narahari D, Chandra TS (1996). Eremothecium ashbyii culture as growth promoter for pure line broiler chicks. Cheiron, 25: 1-2.

Owosibo AO, Odetola OM, Odunsi OO, Adejinmi OO, Lawrence-Azua OO (2013). Growth, hematology and serum biochemistry of broilers fed probiotics-based diets. African Journal of Agricultural Research, 8 (4): 5076-5081.

Rolfe RD (2000). The role of probiotic cultures in the control of gastrointestinal health. The Journal of Nutrition, 130: 396-402.

Ruiz L, Margolles A, Sánchez B (2013). Bile resistance mechanisms in Lactobacillus and Bifidobacterium. Frontiers in Microbiology, 4: 396.

Schneitz C (2005). Competitive exclusion in poultry-30 years of research. Food Control, 16 (8): 657-667.

Shamoto K, Yamauchi K (2000). Recovery responses of chick intestinal villus morphology to different refeeding 
procedures. Poultry Science, 79: 718-723.

Shibat El-hamd DMW, Mohamed H MA (2016). Effect of Probiotics on Salmonella Enteritidis Infection in Broiler Chickens. Egyptian Journal of Chemistry and Environmental Health, 2 (2): 298 -314.

Trafalska E, Grzybowska K (2004). [Probiotics-an alternative for antibiotics]. Wiadomosci Lekarski, 57 (9-10): 491-8.
Tulumoglu S, Yuksekdag ZN, Beyatli Y, Simsek O, Cinar B, Yaşar E (2013). Probiotic properties of lactobacilli species isolated from children's feces. Anaerobe, 24: 36-42.

Weibel ER (1969). Stereological Principles for Morphometry in Electron Microscopic Cytology. In International review of cytology, 26: 235-302. Academic Press. 